\title{
A IMPORTÂNCIA DO APROVEITAMENTO DOS RESÍDUOS INDUSTRIAIS DA SEMENTE DE Citrus
}

\section{THE IMPORTANCE OF THE DEVELOPMENT OF INDUSTRIAL WASTE OF SEED OF Citrus}

\author{
NUNES, P.M.P ${ }^{1}$; SMOLAREK, F.S.F ${ }^{1}$; KAMINSKI, G.A.T. ${ }^{2}$; FIN, M. T. ${ }^{2}$ \\ ZANIN, S. M.W. ${ }^{3}$; MIGUEL, M. D. ${ }^{3}$; MIGUEL, O.G. ${ }^{3}$. \\ $1^{\text {-Mestranda em Ciências Farmacêuticas pela Universidade Federal do Paraná }}$ \\ 2-Acadêmicos do curso de farmácia da Universidade Federal do Paraná \\ 3-Docentes do curso de Farmácia da Universidade Federal do Paraná
}

\section{INTRODUÇÃO}

REC: 02/09 AC:03/09

Os resíduos descartados das indústrias de alimentos poderiam ter uma finalidade benéfica ao homem e ao meio ambiente. Algumas frutas que possuem sementes são processadas para fabricação de alimentos e posteriormente descartadas sendo que poderiam ser utilizadas para minimizar o seu desperdício, Além da possibilidade de ter alto valor agregado quando processados e transformados em subprodutos como óleos vegetais (KOBORI; JORGE, 2005).

Diante destes aspectos uma família grande e interessante a ser discutida é Rutaceae, composto de 140 gêneros e 1300 espécies. Gênero Citrus é um dos gêneros mais importantes, devido a seus frutos, que são estimados em primeiro lugar como alimentos (ANWAR et al., 2008; WAHEED et al, 2009).

As frutas cítricas são dentre as espécies arbóreas as frutas mais importantes do mundo. A produção de laranjas, tangerinas, limões e limas têm aumentado rapidamente. $\mathrm{O}$ gênero Citrus é muito diversificado e é composta de numerosas espécies tais como: Citrus sinensis (Laranja), Citrus paradisi (Toranja), Citrus deliciosa (Mandarim), Citrus limon (Limão) e Citrus aurantifolia (Lima) (SAÏDANI; DHIFI; MARZOUK, 2004).

Os frutos deste gênero são produzidos em vários países. Os Estados Unidos lidera o mundo com um rendimento médio de 30 toneladas por hectare seguido pelo Brasil e China, com 20-25 e 18-20 toneladas, respectivamente (ANWAR et al., 2008). 
O Brasil é um dos maiores produtores e o maior exportador de sucos cítricos (LUZIA; JORGE, 2009). Detém 30\% da produção mundial de laranja e 59\% de suco de laranja. O sistema agroindustrial citrícola movimenta $R \$ 9$ bilhões por ano e gera mais de 400 mil empregos diretos e indiretos. Com o crescimento da competitividade internacional as inovações em pesquisa, tecnologia e logística estão na base da eficiência e liderança do Brasil tanto na atividade produtiva e industrial (JANK; NEVES, 2006)

Com o crescimento da produção dessas indústrias de transformação em todo o mundo, crescem proporcionalmente a disponibilidade de grandes quantidades de sementes Citrus que podem ser utilizadas com maior valor agregado (AKPATA, AKUBOR, 1999).

O alto cultivo deste gênero e o contínuo descarte representam um grande problema ambiental, pois com o aumento da produção e uso esporádico destes resíduos como ração animal e adubo (AKPATA; AKUBOR, 1999), faz com que a não reutilização dos mesmos represente uma propensão de degradação microbiológica. Dessa forma, uma utilização destes resíduos de maneira eficiente, econômica e segura para o meio ambiente, torna-se importante especialmente devido à rentabilidade e aos possíveis empregos que possam gerar (SCHIEBER et al., 2001).

A finalidade deste estudo é mostrar a relevância do aproveitamento de resíduos industriais e demonstrar a importância da realização de novos estudos da semente de Citrus com o objetivo de agregar valor sustentável à fruta enquanto aspectos comerciais e agriculturais pelo aproveitamento do óleo não volátil das sementes de Citrus em produtos alimentícios, cosméticos, entre outros.

\section{DESENVOLVIMENTO DO TEMA}

\subsection{OCORRÊNCIA DE CITRUS}

Os Citrus são originários da Ásia, devido às condições favoráveis para seu desenvolvimento foram introduzidas no Brasil pelos portugueses (COSTA, 2000).

Citrus são reconhecidas como uma das mais importantes fruteiras do mundo. São colhidas em muitos países com clima tropical ou subtropical e os principais produtores são Brasil, China, Japão, México, Paquistão, E.U.A. e os países da 
região do Mediterrâneo. A produção citrícola mundial é de cerca de 105 MT / ano. Os resíduos da indústria de suco, como cascas, sementes e polpas, que representam cerca de $50 \%$ das frutas, é uma fonte potencial de valiosos subprodutos (ANWAR et al., 2008).

\subsection{COMPONENTES QUÍMICOS E BENEFICIAMENTO DAS SEMENTES DE CITRUS}

As frutas cítricas são conhecidas por conterem antioxidantes naturais derivados de seu óleo, sua polpa, semente e casca (LUZIA; JORGE, 2009). A proteção contra doenças tem sido atribuída aos diferentes antioxidantes contidos nos frutos e produtos hortícolas. Estes destacam por constituírem uma das principais fontes de compostos naturais com propriedades antioxidantes, como, por exemplo, carotenóides, ácido ascórbico, fenóis e polifenóis, que protegem o organismo contra o aparecimento de doenças degenerativas (GORINSTEIN et al., 2001). Também podem ser encontradas nas frutas cítricas 6 a $12 \%$ de glicídios, elevadas quantidades de compostos nitrogenados, vitaminas $\mathrm{C}$ e cálcio, bem como ferro, fibras e outros sais minerais (MOULY, GAYDOU, ARZOUYAN, 1999).

Duda-Chodak; Tarko, (2007) ao comparar a atividade antioxidante de cascas e sementes de frutas consumidas na Polônia, percebeu que as cascas possuem maior capacidade de seqüestrar radicais livres e maior concentração de polifenóis que as sementes. Foi relatada também a atividade antioxidante das sementes de laranja, limão e toranja.

Ambas as cascas e as sementes são fontes de compostos fenólicos, que incluem ácidos fenólicos e flavonóides. Flavonóides são representados nas frutas cítricas por duas classes de compostos: flavonas polimetoxiladas e flavanonas glicosilada. Seu padrão é específico de cada espécie, o que os torna bom marcadores de adulteração em sucos comerciais (OOGHE; DETAVERNIER, 1997).

Além disso, alguns flavonóides de Citrus e seus derivados, no campo da tecnologia alimentar, são conhecidos principalmente pela capacidade de proporcionar um sabor amargo ou inibidor da amargura (BENAVENTE- GARCIA et al., 1997). Estes compostos também podem ser usados como antioxidantes naturais 
de óleos e gorduras. Alguns autores relatam como um substituto para os atuais antioxidantes sintéticos e pode trazer benefícios tecnológicos, científicos, nutricionais e medicinais (MARTíNEZ-VALVERDE et al ., 2000). No entanto, o uso destes antioxidantes naturais é limitado pela falta de conhecimento sobre sua composição molecular, quantidade de ingredientes ativos e a disponibilidade de dados relevantes de toxicidade (SHAHIDI; WANASUNDARA, AMAROWICJ, 1994).

Já foram encontradas outras atividades relacionadas a estes flavonóides como: anticâncer, antivirais, atividades antiinflamatórias, efeitos sobre a fragilidade capilar, e uma capacidade de inibir agregação plaquetária. Também podem ser usados diretamente como repelentes (BENAVENTE-GARCIA et al., 1997).

As sementes das frutas cítricas possuem óleo não volátil composto basicamente por triacilgliceróis e, em menor quantidade, por ácidos graxos livres, hidrocarbonetos, esteróis e matéria não-gordurosa como limonina e naringina (GIANNUZZO et al., 2000; KOBORI; JORGE; 2005; REDA et al., 2005).

A naringina é um flavonóide (flavanona glicosilada), que é extraído da casca de alguns Citrus e é o principal responsável por seu sabor amargo. Também está presente na polpa dos frutos, folhas, flores e sementes da planta (GIANNUZZO et al., 2000). Certos flavanonas glicosídeos amargos ou sem gosto podem ser transformados pela abertura do anel na hidrogenação chalcona que mais tarde se transforma em dihydrochalcone, consistindo no poder edulcorante igual ou superior a sacarina (ALVAREZ et al., 2004).

Limonóides são triterpenóides encontrados na Rutaceae e família Meliaceae. Dentre 37 limonóides relatados em Citrus e seus híbridos, limonina é o grande responsável pela amargura retardada em sucos de Citrus e produtos transformados (OZAKI et al., 1991). Os limonóides possuem importantes atividades biológicas tais como a inibição de crescimento de tumores cancerígenos e atividade inseticida. Também existem estudos como antibacterianos, antifúngicos, antimaláricos, antivirais e uma série de outras atividades farmacológicas (ROY; SARAF, 2006; OZAKI et al., 1991).

Dentre as pesquisas de compostos isolados de Citrus várias foram as espécies pesquisadas por Ozaki et al.,(1991), no qual foram identificados os glicosídeos limonóides.Todas as sementes continham 17- $\beta-D$-glucopyranosides de 
limonina, nomilina, obacunone, deacetylnomilina, ácido nomilinico e ácido deacetylnomilinico. O conteúdo total glucosideos limonóides variou 0,31-0,87\% do peso seco. A concentração de glicosídeo nomilina foi maior entre os glicosídeos encontrados nas sementes. Todas as sementes também continham limonóides agliconas comumente encontrados em Citrus, ou seja, limonina, nomilina, deacetylnomilina, obacunone e ichangin

Com relação às atividades biológicas de limonóides as investigações devem ser dirigidas para a caracterização e quantificação. Métodos de extração também devem ser otimizados, avaliação de princípios farmacodinâmica e cinética, e as relações estrutura-atividade deve ser um objetivo chave associada limonóides, para que possam ser facilmente introduzido em nosso arsenal de medicamentos (ROY; SARAF, 2006).

Os ácidos graxos são características importantes do óleo da semente de Citrus. Vários pesquisas são realizadas sobre a composição do óleo não volátil, os principais são: palmídico, palmitoléico, esteárico, oléico, linoléico e linolênico (KOBORI; JORGE; 2005).

- Filsoof e Mehran (1976) investigaram a composição de ácidos graxos de óleos de sementes de oito Citrus Iranianos. Eles pesquisaram de laranjas, tangerina e limões. Os valores para os ácidos graxos majoritários foram: 21,8-29,4\% (ácido palmítico), 3,1-7,60\% (ácido esteárico), 0,3-1,3\% (ácido palmitoléico), 23,532,3\% (ácido oléico), 33,5-39,8\% (ácido linoléico) e 3,1-7,6\% (ácido linolênico). Pequenas quantidades (até $0,1 \%$ ) de ácidos mirístico e araquídico.

- Habib et al. (1986) investigaram a composição química das sementes de citros egípcios como potenciais fontes de óleos vegetais. Foram analisadas as sementes das frutas cítricas laranja, tangerina, limão e toranja. Foram extraídos com éter de petróleo e foi obtido um rendimento superior a 40\%. Eles acrescentaram que, o aspecto nutricional óleos das sementes de Citrus são semelhantes a outros óleos vegetais com um conteúdo relativamente alto de ácido linoléico e linolênico.

- Trandjiiska e Nguyen (1989) estudaram a composição de triacilglicerideo dos óleos de sementes de Citrus do Vietnã. Observaram que a percentagem de rendimento de óleo de semente de alguns citrus originários do Vietnã foi de 55- 
60\% (laranja), 60-65\% (toranja), 48-50\% (tangerina) e 40-46\% (limão). Eles também observaram que o teor de óleo foi relativamente alto em comparação com outras sementes oleaginosas tradicionalmente utilizadas como fontes de óleos comestíveis. As análises demonstraram que ácido linoléico é o ácido graxo mais importante em todas as sementes de Citrus, exceto para o limão, no qual o teor de ácido oléico foi o mais importante.

- De acordo com Ajewole e Adeyeye (1993) os óleos de sementes de citros da Nigéria possuem rendimento de $24 \%$ a $41 \%$, com propriedades físico-químicas e composição de ácidos graxos comparáveis aos óleos vegetais de boa qualidade, podendo ser utilizados para o consumo humano. São compostos basicamente por triacilgliceróis, em menor quantidade, por ácidos graxos livres, hidrocarbonetos, esteróis e matéria não-gordurosa como limonina e naringina. Os gêneros estudados incluem Citrus sinensis, C. paradisi, C. aurantium, $C$. reticulata, $C$. aurantifolia e tangelo (um híbrido entre $C$. paradisi e $C$. reticulata) e os principais ácidos graxos encontrados foram palmítico (12 a $28 \%$ ), oléico (entre 26 e 45\%) e linoléico (entre 29 e 38\%). Foram encontrados também ácido esteárico e linolênico. Os óleos apresentaram alto grau de insaturação, entre 67 e $86 \%$.

- Segundo Akpata e Akubor (1999) o óleo de sementes de Citrus contém alta quantidade de ácidos graxos insaturados e quando refinados podem ser utilizados na formulação de óleos comestíveis e sopa industrializada. Relatam que as sementes de laranja são uma boa fonte de gordura, hidratos de carbono, fibra bruta, cálcio, potássio e sódio, baixo conteúdo proteína e ferro e que a farinha de sementes de laranja também possuem grande importância na incorporação produtos para alimentação humana como ingrediente funcional. Desta forma, constatou-se que sementes de Citrus possuem uma fonte potencial de óleo, sendo valioso na aplicação de Indústrias de alimentos e outras aplicações industriais.

- De acordo com El-Adawy et al. (1999), as sementes são ricas em óleo e proteína, e possui boa fonte de $\mathrm{K}, \mathrm{Ca}, \mathrm{Na}, \mathrm{Fe}$ e Mg. Estes também são ricos em limonóides e seus derivados.

- Estudos de Fernandes et al, (2002), no qual foi extraído o óleo da semente de 
frutas cítricas do Brasil, com solvente hexano, através do aparelho soxhlet obteve-se um rendimento de 24,27\% (Citrus sinensis), 24,62\% (C.limon) e $28,35 \%$ (C. reticulata). As extrações realizadas apenas com Citrus sinensis e $C$. reticulata em condições de extração com fluido supercrítico de dióxido de carbono obteve rendimento de $37,00 \%$ e $26,5 \%$ respectivamente. Foram encontrados na extração por soxhlet Ác. palmítico (C.limon) 29,8\%, (Citrus sinensis) 53,9\%, (C. reticulata) 38,6\%. Ac. linoléico (C.limon) 24,1\%, Citrus sinensis 29,6\%, (C. reticulata).30,5\%. Ac. linolênico (C.limon) 38,7\%, (Citrus sinensis) 13,5\%, (C. reticulata).19,9\%. Ac. oléico (C.limon) 2,4\%, (Citrus sinensis) 0,7\%, (C. reticulata).2,1\%. Ac. esteárico (C.limon) 5,0\%, (Citrus sinensis) 2,3\%\%,(C. reticulata) 8,9\%. Estes óleos indicaram atividade antifungica. O extrato hexanico sementes $C$ limon se mostrou mais ativo, na concentração de $200 \mu \mathrm{m} / \mathrm{mL}$ e resultou na inibição de $60 \%$ do crescimento do fungo Leucoagaricus gongylophorus, simbionte das formigas cortadeiras. E dentre os três óleos estudados, o que possui maior atividade inseticida para formigas cortadeiras foi o $C$. reticulata

- Sementes de variedades de frutas cítricas da Tunísia, ou seja, Laranja (Citrus sinensis), Limão (Citrus limon)., bergamota ( Citrus bergamia) e laranja amarga (Citrus aurantium) foram analisadas a composição e o rendimento . A semente de limão apresentou maior rendimento (78\%), a laranja $(51,8 \%)$ e a bergamota e laranja amarga (26\%). Foi utilizado como solvente na extração o éter de petróleo. Os principais ácidos graxos encontrados foi palmítico, oléico e linoléico. Observou-se que os ácidos graxos insaturados são mais abundante do que os ácidos graxos saturados (SAÏDANI; DHIFI, MARZOUK; 2004)

- Reda et al, (2005) identificou no óleo das sementes de limão rosa do Brasil os seguintes ácidos graxos na forma de ésteres metílicos: caprílico (0,90\%), palmítico $(21,40 \%)$, esteárico $(2,60 \%)$, oléico $(21,20 \%)$, linoléico $(43,00 \%)$, linolênico $(7,60 \%)$ e araquídico $(0,20 \%)$ e no óleo das sementes de limão siciliano: caprílico $(1,00 \%)$, mirístico $(0,10 \%)$, palmítico $(19,60 \%)$, esteárico $(3,00 \%)$, oléico $(28,60 \%)$, linoléico $(34,40 \%)$, linolênico $(10,00 \%)$ e araquídico $(0,20 \%)$. Os resultados indicaram que ambos os óleos apresentam estabilidade térmica até $250^{\circ} \mathrm{C}$, composição química semelhante e alto teor de ácidos graxos 
insaturados $(71,80$ e 73,00\%). Pela composição de ácidos graxos também foi possível determinar a provável composição em triacilgliceróis dos óleos. Os resultados mostraram que os óleos apresentam características semelhantes a óleos comestíveis de boa qualidade.

- No estudo de Anwar et al. (2008) os óleos de sementes de citros do Paquistão consistiram principalmente de ácido linoléico (36,1-39,8\%). Outros ácidos graxos foram encontrados como ácido palmítico (25,8-32,2\%), ácido oléico (21,924,1\%), ácido linolênico (3,4-4,4\%), e ácido esteárico (2,8-4,4\%). O conteúdo de tocoferóis (Alfa, gamma, e delta) no óleo foram 26,4-557,8, 27,7-84,1, e 9,1 $20,0 \mathrm{mg} / \mathrm{kg}$, respectivamente. Os resultados deste estudo demonstram que as sementes de Citrus destas espécies investigadas são uma fonte potencial de óleo que pode ter valor em indústrias de alimentos e ser utilizado para outras aplicações industriais (ANWAR, 2008).

- Waheed et al. (2009) pesquisou três espécies de Citrus, Citrus sinensis, Citrus paradisi, Citrus aurantium do Paquistão, no qual analisou os constituintes de lipídeos totais e classes de lipídios neutros, ou seja, os hidrocarbonetos, ésteres de cera, ésteres de esterol, triacilgliceróis, ácidos graxos livres, 1,3diacilgliceróis, 1,2-diacilgliceróis, esteróis, álcoois, e monoacilgliceróis. Ácido Palmítico, linoléico e oléico foram os principais componentes das classes lipídicas estudadas.

Apesar de sua composição e das atividades existentes nas frutas citricas, a maior parte das cascas e as sementes permanecem não utilizadas. (KOBORI, NEUZA; 2005). Pesquisas de novos componentes das sementes de Citrus são de grande importância, mas pouco tem sido relatado (ANWAR et al., 2008).

\subsection{EXTRAÇÃO DO ÓLEO DAS SEMENTES DE CITRUS}

Para se extrair o óleo de sementes vegetais empregam-se extrações com solventes orgânicos (maior rendimento) ou por prensagem das sementes (menor rendimento). Extração usando fluido supercrítico também é utilizada, no qual os óleos vegetais podem ser extraídos com fluido de dióxido de carbono. Neste último método os rendimentos obtidos dependem da pressão e da temperatura empregada 
durante a extração, bem como o tamanho e o formato das partículas de semente (STAHL; SCHUTZ; MANGOLD, 1980)

$\mathrm{Na}$ pesquisa realizada por Fernandes et al. (2002) foi comparado dois métodos de extração do óleo das sementes (Citrus sinensis, Citrus. limon e Citrus reticulata) com solvente hexano em aparelho soxhlet e extração por fluido supercrítico (CO2) e observou que o óleo da primeira extração citada, apresentou compostos voláteis tais como terpenos e álcoois graxos, ésteres e aldeídos. No entanto, os óleos obtidos por extração com fluido supercrítico apresentou triglicerídeos apenas. Estes resultados indicam que a extração utilizando fluido supercrítico apresenta maior seletividade. Porém os óleos obtidos das extrações possuem pouca diferença qualitativa e estão dentro das faixas de porcentagens obtidas em diversas variedades de Citrus. (FERNANDES et al., 2002).

\subsection{ASPECTOS ECONÔMICOS}

Citrus estão entre as mais importantes árvores fruteiras no mundo e seus processos de produção e consumo tem aumentado consideravelmente desde os meados da década de 1980 (STEUER; SCHULZ; LAGER, 2001). Este fato se deve ao aumento do consumo de produtos naturais e por conseqüência tem estimulado o aumento da produção de citros no Brasil, levando assim o país à liderança mundial na exportação de suco de laranja concentrado (FERNANDES et al., 2002). A citricultura brasileira se destaca e apresenta competitividade importante dentre as atividades agroindustriais (CARVALHO, 2003).

Os citros possuem grande importância econômica devido a seus variados usos. Os óleos essenciais de várias plantas cítricas são obtidos por prensagem ou destilação de frutos e cascas de frutas. Eles são amplamente utilizados na indústria de perfumes, fragrâncias, produtos de beleza, desodorizantes, sabões e detergentes. Além disso, vários tipos de óleos essenciais de Citrus estão disponíveis para as indústrias de alimentos._Eles também são utilizados como componentes de produtos farmacêuticos, anti-sépticos e aromaterapia. No entanto, a importância de Citrus não está somente no seu óleo essencial, mas também nos componentes de suas sementes que contêm diferentes elementos que podem ser usados para produção de uma série de outros produtos (SAÏDANI; DHIFI; MARZOUK, 2004). 
As sementes de citros, habitualmente são consideradas resíduos agroindustriais, muitas vezes são utilizados como ração animal ou fertilizante, porém o custo de secagem e transporte para esse fim é um fator economicamente limitante, (KOBORI; JORGE, 2005). Estes poderiam ter outras utilidades, pois grande parte do resíduo sólido das sementes de citros é uma fonte inexplorada de óleo não volátil que pode alcançar 55\% de rendimento (FERNANDES et al., 2002). Apesar de 0 Brasil ter uma grande produção de laranjas, existe poucos estudos sobre seus subprodutos e o aproveitamento destes resíduos (BORTOLUZZI; MARANGONI, 2006).

Atualmente existe crescente demanda por antioxidantes naturais e inúmeras investigações científicas especialmente entre os frutos, mas apenas alguns deles envolvem resíduos de frutos, sementes e cascas. Esforços têm sido feitos para melhorar os métodos para utilização destes resíduos A concorrência entre os antioxidantes naturais e sintéticos, em termos de consumo, aceitação, as necessidades legais de acesso ao mercado, a toxicidade e estabilidade térmica, além do melhor método de extração, são os problemas da não utilização adequada dos resíduos até o momento (DUDA-CHODAK; TARKO, 2007)

\section{CONCLUSÃO}

De acordo com as circunstâncias fica claro a grande relevância o aproveitamento de resíduos industriais. A utilização de sub-produtos da indústria de Citrus é altamente desejável. Os componentes das sementes devem ser melhor estudados a fim de se obter seus constituintes puros ou frações que tenham alto valor agregado. Visto que os depósitos contínuos desse descarte poderiam aumentar o custo do processamento dos produtos e agravar a poluição ambiental.

\section{REFERÊNCIAS}

AJEWOLE, K.; ADEYEYE, A. Characterization of Nigerian citrus seed oils. Food Chemistry, v. 47, p. 77-78, 1993. 
AKPATA M.I.; AKUBOR, P.I. Chemical composition and selected functional properties of sweet orange (Citrus sinensis) seed flour. Plant Foods for Human Nutrition. v. 54, n. 4 , p. 353-362, 1999.

ALVAREZ, M. J. M.; CAMACHO, D. R. B.; SANCHEZ, M. P. et al. Evaluación de la actividad antioxidante de extractos de flavonóides de cáscara de naranja en el aceite de soja desodorizado.INCI. vol.29, n.9, p.532-538, 2004.

ANWAR, F.; NASEER, R.; BHANGER, M I; ASHRAF, S.; TALPUR, F. N.; ALADEDUNYE, F. A. Physico-Chemical Characteristics of Citrus Seeds and Seed Oils from Pakistan. Journal of the American Oil Chemists' Society. V. 85, p.321330, 2008.

BENAVENTE-GARCIA, O.; CASTILLO, J.; MARIN, F. R.; ORTUNO, A.;DEL RIO, J. A. Uses and properties of Citrus flavonoids. J.Agric. Food Chem. 1997, 45, 45054515.

BORTOLUZZI, R. C; MARANGONI, C. Caracterização da fibra dietética obtida da extração do suco de laranja. Revista Brasileira de Produtos Agroindustriais, Campina Grande, v.8, n.1, p.61-66, 2006

CARVALHO, R. de. Variabilidade cromossômica e relação entre espécies e cultivares de Citrus L,133f. Tese (Doutorado) em Ciências Biológicas, Universidade Federal de Pernambuco. Recife, 2003.

COSTA, A.F. Farmacognosia. 3.ed. Lisboa: Calouste Gulbenkian, 2000.

DUDA-CHODAK A, TARKO T. Antioxidant properties of different fruit seedsandpeels.Acta Sci Pol Technol Aliment 2007;6:29-36.

EL-ADAWY T., RAHMA E.H., EL- BEDAWY A.M. Properties of some Citrus seeds. Part 3. Evaluation as a new source of protein and oil. Nahrung, v. 43, p. 385-391, 1999. 
FERNANDES, J.B.; et al. Extrações de óleos de sementes de citros e suas atividades sobre a formiga cortadeira Atta sexdens e seu fungo simbionte. Química Nova, n. 6B v. 25, p. 1091-1095, 2002.

FI LSOOF, M; MEHRAN, M. Fatty Acid Composition of Iranian Citrus Seed Oils. Journal of the American of Iranian. v. 53, n. 10, p. 654-655, 1976.

GIANNUZZO, A. N.; NAZARENO, M. A.; MISHIMA, H. T. and LOPEZ DE MISHIMA, B. A.. Extracción de naringina de Citrus paradisi L. estudio comparativo y optimización de técnicas extractivas. Ciência e Tecnologia de Alimentos. 2000, v.20, n.2, p. 257-261.

GORINSTEIN, S.; BELLOSO-MARTIN, O.; PARCK, Y-S.; HARUENKIT, R.;LOJEK, A.; CÍZ, M.; CASPI, A.; LIBMAN, I.; TRAKTHENBERG, S. Comparison of some biochemical characteristics of different citrus fruits. Food Chemistry, v. 74, p. 30915,2001

HABIB MA, HAMMAM MA, SAKR AA, ASHOUSH YA Chemical evaluation of Egyptian citrus seeds as potential sources of vegetable oils. Journal of the American Oil Chemists' Society, v. 3, p.1192-1197, 1986

JANK, M.; NEVES, M. Perspectivas da cadeia produtiva da laranja no Brasil: a agenda 2015. 2006. Disponível em:http://www.fundacaofia.com.br/pensa/downloads/ Agenda_Citrus_2015_PENSAICONE.pdf>. Acesso em: maio 2010.

KOBORI, C.N; JORGE, N. Caracterização dos óleos de algumas sementes de frutas para aproveitamento de resíduos industriais. Ciências e agrotecnologia., Lavras, v. 29, n. 5, p. 1008-1014, 2005.

LUZIA, D. M. M. L.; JORGE, N. Atividade antioxidante do extrato de sementes de limão (Citrus limon) adicionado ao óleo de soja em teste de estocagem acelerada. Quimica Nova, v.32, n.4 p. 1-4, 2009. 
MARTINEZ-VALVERDE, I.; PERIAGO, M.J.; ROS, G. Significado nutricional de los compuestos fenólicos de la dieta. Arch. Latinoam. Nutr., Caracas, v.50, n.1, p.5-18, 2000.

MOULY, P.P.; GAYDOU, E.M.; ARZOUYAN, C. Separation and quantification of orange juices using liquid chromatography polymethoxylated flavones. Analusis, v. 27, p. 284-8, 1999.

OOGHE, W. C.; DETAVERNIER, C. M. Detection of the addition of Citrus reticulata and hybrids to Citrus sinensis by flavonoids.J. Agric. Food Chem. 1997, 45, 16331637.

OZAKI Y, FONG CH, HERMAN Z, MAEDA H, MIYAKE M, IFUKU Y, et al. Limonoid glucosides in citrus seeds. Agric Biol Chem, p. 137-41. 1991

REDA, Seme Youssef et al. Caracterização dos óleos das sementes de limão rosa (Citrus limonia Osbeck) e limão siciliano (Citrus limon), um resíduo agroindustrial. Ciênc. Tecnol. Aliment., vol.25, n.4, p. 672-676, 2005.

ROY A, SARAF S. Limonoids: overview of significant bioactive triterpenes distributed in plants kingdom. Biol Pharm Bull, p.191-201, 2006

SAIDANI, M; DHIFI , W.; MARZOUK, B. Lipid evaluation of some Tunisian citrus seeds. Journal of Food Lipids, v.1, p.242-250, 2004.

STAHL, E.; SCHUTZ, E.; MANGOLD, H. K.; J. Extraction of Seed Oils with Liquid and Supercritical Carbon Dioxide. Agric. Food Chem. 1980, 28, 1153.

SHAHIDI, F., WANASUNDARA, U. N., \& AMAROWICJ, R. Natural antioxidant from low pungency mustard flour. Food Research International, v. 27, p. 489-493, 1994.

SCHIEBER, A.; STINTZING, F. C.; CARLE, R. Byproducts of plant food processing as a source of functional compounds: recent developments. Trends Food Science Technology, Cambridge, v. 12, p. 401-413, 2001. 
STEUER, B., SCHULZ, H.; LAGER, E. Classification and analysis of Citrus oils by NIR spectroscopy. Food Chemistry. 72, 113-117, 2001.

TRANDJISKA, R; NGUYEN, H. Triglyceride composition of seed oils from Vietnamese citrus fruits. Riv Ital Sost Grasse, p. 99-100, 1989.

WAHEED, A., MAHMUD, S., SALEEM, M., AHMAD, T. Fatty acid composition of neutral lipid: Classes of Citrus seed oil. Journal of Saudi Chemical Society. Vol.13, p.269-272, 2009 